\title{
The Effect of Using Physical Exercise in Reducing Stress in Light of Corona Pandemic Among the Students of Second Stage, Department of Physical Education and Sports Sciences - Al-Maarif University College
}

\author{
Ahmed Khaled Awad*, Doaa Mohebuddin Ahmed \\ Department of Physical Education and Sports Sciences, Al-Maarif University College, Anbar, Iraq \\ *a.k.awad@uoa.edu.iq
}

\begin{abstract}
:
The first chapter contains the introduction to the research and its importance, which includes physical exercises, which are necessary for the individual in order to live a healthy life free from diseases, impairments and epidemics, as well as being a means of pleasure, psychological comfort and achievement of achievement for its practitioners, and it is one of the most important means that reach students to the highest levels in achieving performance Kinetic, whether in the sports field or in other areas of life, which helps them get rid of psychological tension and pressures and enjoy a healthy life free from mental illnesses and distortions, and here lies the importance of research in identifying the effect of using physical exercises in reducing psychological tension among students of the Department of Physical Education and Sports Sciences College University knowledge. As for the research problem, it is that the contemporary world is witnessing recently the emergence of a major crisis, which is the Corona virus, which negatively affected students of the Department of Physical Education and Sports Sciences because of their sitting at home, which led to their exposure to psychological pressure and tension and fear of not being able to practice sports activity normally and being The researchers are teachers and have experience in their field of specialization, they have developed a set of physical exercises that students can practice while they are at home and that affect the reduction of psychological tension for them and the exploitation of leisure time in addition to it provides them with energy and energy, relieves them from psychological pressure and gives them beautiful strength and makes them enjoy a healthy \& good state.
\end{abstract}

Keywords: Influence; Exercises; Tension; Pandemic; Drop.

Crossref doi https://doi.org/10.51345/.v31i1.222.g148 

تأثير استخدام التحارين البدنية في خفض التوتر في ظل جائحة كورونا لدى طلاب المرحلة الثانية قسم التربية البدنية وعلوم الرياضة - كلية المعارف الجامعة

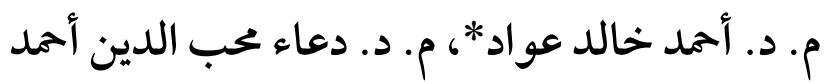 قسم التربية البدنية وعلوم الرياضة، كلية المعارف الجامعة، الأنبار، العراق
*a.k.awad@uoa.edu.iq

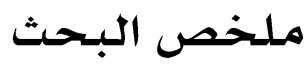

احتوى الباب الأول على مقدمة البحث وأهميته التي تضمن التحارين البدنية والتي تعد ضرورية للفرد من اجل ان يجيى حياة سليمة خالية من الامراض والعاهات والاوبئة فظلاً عن كونها وسيلة للمتعة والراحة النفسية وتحقيق الإنجاز عند ممارسيها وهي من اهم الوسائل التي تصل بالطلاب الم اعلى مستويات في تحقيق الأداء الحركي سواء في المجال الرياضي او في بجالات الحياة الأخرى والتي تساعدهم على التخلص من التوتر النفسي والضغوطات والتمتع بحياة صحية خالية من الامر اض النفسية والتشوهات أوهنا تكمن اهمية البحث في التعرف على تأثير استخدام التحارين البدنية في خفض التوتر النفسي لدى طلاب قسم التربية البدنية وعلوم الرياضة كلية المعارف الجحامعة ـ اما مشكلة البحث فهي ان العالم المعاصر يشهد في الآونة الاخيرة ظهور ازمة كبيرة وهو فايروس كورونا والذي اثر بشكل سلبي على طلاب قسم التربية البدنية وعلوم الرياضة بسبب جلوسهم في المنزل مما أدى الى تعرضهم لضغط وتوتر النفسي والخوف من عدم القدرة على ممارسة النشاط الرياضي بصورة طبيعية ولكون الباحثين هما تدريسين وذو خبرة في مجال تخصصهم فقد قاما بوضع بمموعة من التحارين البدنية التي من الممكن ان يمارسها الطلاب وهم في منازلهم والتي تؤثر في خفض التوتر النفسي لهم ولاستغلال أوقات الفراغ وبالإضافة انها تمدهم بالنشاط والطاقة وتخلصهم من الضغوط النفسية وتكسبهم القوام الجميل وتجعلهم يتمتعون بحالة صحية جيدة.

Crossref doi https://doi.org/10.51345/.v31i1.222.g148 
المقدمة

ان من أولى اهتحمات التدريسين هو تعلم طلابهم المهار ات الرياضية واتقانها والوصول بهم الى مرحلة الالية ولغرض الوصول الى هذه المرحلة لا بد من تنظيم وجدولة التمارين البدنية خلال البرنامج التعليمي وذلك لتسهيل عملية التعلم أوتعد التمارين البدنية ضرورية للفرد من اجل ان يحيى حياة سليمة خالية من الامراض والعاهات والاوبئة فظلاً عن كونها وسيلة للمتعة و الراحة النفسية وتحقيق الإنجاز عند ممارسيها وهي من اهم الوسائل التي تصل بالطلاب الى اعلى مستويات في تحقيق الأداء الحركي سواء في المجال الرياضي او في مجالات

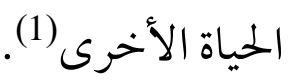

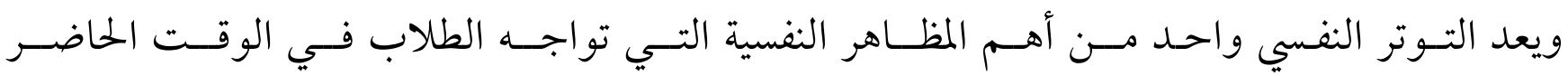
الملـيء بالتعقيدات والمطالب الكثيرة ، وتصادفهم في مو اقف مو اقف خختلفة والتي تحتاج إلى مو اجهة وحلـول عاجلـة وفورية

وان الظروف التي يمر بها العالم بسبب الجائحة تسبب بجلوس الطلاب في منازلهم مما جعلهم يمرون بحالة قلق وتوتر نفسي اثر عليهم فقاما الباحثين بوضع بجموعة من التمارين البدنية التي تساعد الطلاب في خفض التوتر النفسي ولاستغلال اوقات الفراغ في ممارسة التحارين البدنية ومن اجل المحافظة على الصحة النفسية والجسدية. وهنا تكمن اهمية البحث في التعرف على تأثير استخدام التحارين البدنية في خفض التوتر النفسي لدى طلاب قسم التربية البدنية وعلوم الرياضة كلية المعارف الجامعة أما مشكلة البحث فهي يشهد العالم المعاصر في الآونة الاخيرة ظهور ازمة كبيرة وهو فايروس كورونا والذي اثر بشكل سلبي على طلاب قسم التربية البدنية وعلوم الرياضة بسبب جلوسهم في المنزل مما أدى الى تعرضهم لضغط وتوتر النفسي والخوف من عدم القدرة على ممارسة النشاط الرياضي بصورة طبيعية ولكون الباحثين هما تدريسين وذو خبرة في مجال تخصصهم فقد قاما بوضع بجموعة من التحارين البدنية التي من الممكن ان يمارسها الطلاب وهم في منازهم والتي تؤثر في خفض التوتر النفسي لهم ولاستغلال أوقات الفراغ وبالإضافة انها تمدهم بالنشاط والطاقة وتخلصهم من الضغوط 
النفسية وتكسبهم القوام الجميل وتجعلهم يتمتعون بحالة صحية جيدة أما اهداف البحث فهي التعرف على درجة التوتر النفسي لدى طلاب المرحلة الثانية قسم التربية البدنية وعلوم الرياضة في كلية المعارف الجامعة ألتعرف على تأثير التحارين البدنية في خفض التوتر النفسي لدى طلاب المرحلة الثانية قسم التربية البدنية وعلوم الرياضة في كلية المعارف الجامعة، اما فرضيتا البحث فهي هناك فروق ذات دلالة إحصائية بين نتائج الاختبارات القبلية والبعدية لمجموعتي البحث الضابطة والتجريبية في خفض التوتر النفسي للطلاب، هناك فروق ذات دلالة إحصائية بين بجموعتي البحث الضابطة والتجريبية في نتائج الاختبارات البعدية في خفض التوتر النفسي للطلاب.

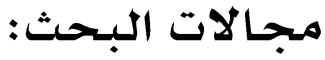

المجال البشري:- عينه من طلاب المرحلة الثانية قسم التربية البدنية وعلوم الرياضة كلية المعارف الجامعة

$$
\text { للعام الدراسي } 2019 \text { - } 2020
$$

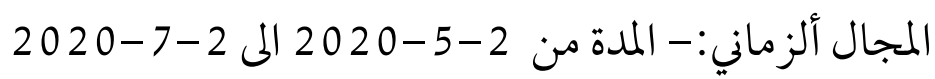$$
\text { المجال المكاني :- المنزل الخاص بالطلاب }
$$

تحديد المصطلحات:

التمارين البدنية :- عبارة عن حركات عدة او تكرار أداء حركي يؤدي بغرض معين تحت أسس علمية فسيولوجية وتشريكية وتربوية .

التوتر النفسي:(2) بأنــه "ظــاهرة غيــر مرئية ينـتج عنهـا شـعور بالتهديد والاضـطر اب و العصبية والحساسية الزائدة تجعل الفرد غير قادر على التكيف مع البيئة التي يعيش فيها وتنعكس على سلوكه مع الآخرين".

\section{منهج البـحث:}

استخدم الباحثان المنهج التجريبي وبتصميم المجموعتين الضابطة والتجريبية ذات الاختبارين القبلي والبعدي لملائمته طبيعة مشكلة البحث. 


\section{مجتمع البحث وعينته}

تحدد مجتمع البحث بطلاب المرحلة الثانية في كليه المعارف الجامعة قسم التربية البدنية وعلوم الرياضية للعام الدراسي (2019- 2020) والبالغ عددهن (228) طالب للدراستين الصباحية والمسائية، مقسمين (115) طالب من الدراسة الصباحية و (113 ) طالب من الدراسة المسائية تم استبعاد (10 ) طلاب من عينة البحث من اجل التجربة الاستطلاعية، وتم استبعاد (18) طالب لم نتمكن من الوصول اليهم بسبب ظروفهم الخاصة، فكانت عينة البحث ( 100 ) طالب للمجموعة التجريبية و ( 100 ) طالب للمجموعة الضابطة.

\section{الوسائل والاجهزة والأدوات}

Zoom الانترنيت برنامج

2 - استمارة استطلاع الخبراء

$$
\text { 3- استمارة استبانة رأي }
$$$$
\text { 4- مقياس التوتر النفسي }
$$

5 - استمارة لتفريغ بيانات نتائج المقياس

$$
6 \text { - الوسائل الإحصائية }
$$

\section{اجراءت البحثث الميدانية}

\section{تحديد مقياس التوتر النفسي}

لقد قاما الباحثين بالاطلاع على العديد من المصادر والمراجع العلمية والدراسات والبحوث لغرض إيجاد مقياس التوتر النفسي يلائم عينة البحث ولم يجدوا سوى المقياس المعد من قبل احمد أبو اسعد لسنة (2011) إذ تـالف المقياس بـصورته النهائية مـن (35 ) فقرة، موزعـة على (ثلاث ابعاد )، كما موضح في ملحق رقم (2)، بعد ذلك قاما الباحثين بعرض فقرات المقياس على بجموعة الخبراء والمختصين في بجال الاختبارات والقياس وعلم النفس لمعرفة مدى ملائمة فقرات المقياس لطلاب وطالبات قسم التربية البدنية 
وعلوم الرياضة في كلية المعارف الجامعة وقياسها للتوتر النفسي، وبعد جمع الاستمارات وتفريغها تبين مدى اتفاق الخبراء على مدى صلاحية الفقرات المقياس إضافة إلى ملائمته لعينة البحث.

\section{أسلوب التصحيح مقياس التوتر النفسي (مفتاح الاختبار ):}

لحساب الدرجة التي يكصل عليها المجيب من خلال إجابته عن فقرات المقياس اعتمد الباحثين تصحيح المقياس اذ تتم الإجابـة عـن فقرات المقياس مـن خهلال (ثلاث) بـدائل هي (تنطبق علي كثيراً ، تنطبق علي أحيانا، لا تنطبق علي) تعطى هـا الأوزان (تنطبق علي كثيراً درجتان، تنطبق علي أحيانا درجة واحدة، لا تنطبق علي صفر درجة) علناً ان جميع فقرات المقياس ايجابية وان اعلى درجة للمقياس هي (70) وتعني درجة عالية من التوتر النفسي وادنى علامة هي صفر وتعني درجة منخفضة من التوتر النفسي.

\section{أسس العلميية لمقياس التوتر النفسي}

الصدق الظاهري: تم عرض المقياس على بجموعة من الخبراء المختصين في علم النفس العام والرياضي وحصل الباحثين على نسبة اتفاق بلغت 100 \% ثبات المقياس: تم استخر اج الثبات وذلك باستخدام بطريقة ألفا كرونباخ لأجل التأكد من ثبات المقياس وتم تطبيق المقياس، على عينة استطلاعية مكونة من (5 طلاب) من خارج التجربة الرئيسية، اذ بلغ الثبات 0.93 وهذا يدل على ان المقياس يتمتع بدرجة ثبات عالية. الموضوعية: أما موضوعية الاختبار، فقد تمت الاستعانة بآراء الخبراء حول موضوعيته، وقد تم اتفاق الخبراء حول مدى صلاحية المقياس، وأنها لا تخضع للتقديرات الشخصية، وإنها هناك درجات للإجابة.

\section{تحديد التمهارين البدنية:}

من خلال خبرة الباحثين المتو اضعة كونهم تدريسيين تم اختيار بجموعة من التمارين البدنية المناسبة التي تخدم عينة البحث وتم توزيعها على الخبراء لمعرفة مدى ملائمتها لمستوى العينة وبعد اتفاق الخبراء على صلاحيتها

وملائمتها لمستوى العينة تم اعتمادها وتم ذكر بجموعة منها كما موضحة في ملحق رقم (1). 


\section{التجارب الاستطلاعية:}

من التوصيات المهمة التي يوصي بها خبراء البحث العلمي لغرض الحصول على نتائج دقيقة موثوق بها أجراء التجربة الاستطلاعية وكما قاما الباحثين بأجرائها عن طريق الانترنيت وبرنامج Zoom بيومين متتاليين اذتم إجراء التجربة الاستطلاعية الأولى الخاصة بمقياس التوتر النفسي يوم السبت المصادف 2/ 2020 / 20 على عينة التجربة الاستطلاعية البالغ عددهم (10 ) طلاب من كلية المعارف الجامعة / قسم التربية البدنية وعلوم الرياضةًا وفي اليوم الاحد الموافق 3/5/ 2020 تم إجراء تجربه استطلاعيه للاختبارات البدنية عن طريق

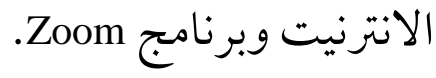

\section{الاختبـارات القبلية:}

قام الباحثان بأجراء الاختبارات القبلية لعينة البحث والبالغ عددهم (200) طالب يوم الاثنين بتاريخ ( / / / 2020 ) عن طريق الانترنيت وبرنامج Zoom كما قاما الباحثين بتوضيح تعليمات المقياس بشكل دقيق، إذ طلبا من الطلاب الإجابة عن فقرات المقياس بشكل صادق وموضوعي ألما له من أهمية كبيرة للبحث

$$
\text { واتبع الباحثان الخطو اتلمملية التربوية. }
$$

1 - ارسال الاستبانة عن طريق الانترنيت مع تهيئة اللوازم المطلوبة لأفر اد العينة للإجابة عن المقياس .

2 - ضمان كتابة أفر اد العينة الاسم والشعبة بالتفصيل .

3 - شرح التعليات الخاصة بالاستبانة وطريقة الإجابة عنها وتوضيح مثال لكل إجابة . 4 - التأكد من فهم أفر اد العينة طريقة الإجابة .

واستغرق زمن الاجابة عن فقرات المقياس (25 دقيقة) وبعد انتهاء الطلاب من الإجابة تم إعادة ارسال الاستمارات وتفريخ نتائجها في استمارات خاصة لسهولة العمل الإحصائي. وقبل الشروع بالتجربة الرئيسية مع ضبط كافة المتغيرات ولكي يكون عمل الباحثين من خط شروع واحد ويعد أن تم تقسيم بجموعتي البحث الضابطة والتجريبية وللتأكد من عدم وجود فروق معنوية بين 
المجموعتين قاما الباحثين بأجراء التكافؤ بينهم في الاختبارات القبلية المتضمنة التحارين البدنية العملية كما

موضح في الجدول رقم (1)

الجدول (1 ) يبين تكافؤ مجموعتي البحث (التجريبية والضابطة) في مقياس التوتر النفسي تحت مستوى دلالة 0.05

\begin{tabular}{|c|c|c|c|c|c|c|c|c|c|c|c|}
\hline \multirow[b]{2}{*}{ الإحصائية } & \multirow{2}{*}{ مستوى الحطأ } & \multirow[b]{2}{*}{ قلمحسوة ت } & \multicolumn{3}{|c|}{ المجمموعة الضابطة } & \multicolumn{3}{|c|}{ المجموعة التجريبية } & \multirow[b]{2}{*}{ القياس } & \multirow[b]{2}{*}{ المتغيرات } & \multirow[b]{2}{*}{ ت } \\
\hline & & & $\varepsilon$ & س - مس & ن & $\varepsilon$ & س - مس & ن & & & \\
\hline غير معنوي & 0,286 & 0,453 & 4,632 & 48,93 & 100 & 5,272 & 48,61 & 100 & الدرجة & التفوتر & 1 \\
\hline
\end{tabular}

تنفيذ الدراسة الرئيسلة:

قبل البدء بتطبيق التمارين البدنية قام الباحثان بقياس مستوى التوتر للطلاب عن طريق توزيع الاستبانة والتواصل معهم عن طريق الانترنيت ولاحظا ان الطلاب يتعرضون لتوتر عالي بسبب الظروف الراهنة التي يمر بها البلد والذي تسبب بجلوسهم في المنزل وعلى هذا الأساس قاما الباحثين باختيار بجموعة من التحارين البدنية التي تساعد الطلاب على خفض التوتر واستغلال أوقات فراغهم في ممارسة هذه التمارين وتم عرضها على الخبراء لبيان مدى أهميتها وملائمتها لمستوى العينة وبعد الحصول على الموافقة تم تطبيقها على عينة البحث الرئيسية من خلال التو اصل مع الطلاب عبر الانترنيت وبرنامج Zoom في يوم الثلاثاء الموافق 5-520 20 ولغاية يوم الاحد الموافق 28 /6 20 / 20 بواقع ثلاث أيام بالأسبوع (الاحد - الثلاثاء - الخميس) وتم شرح التمارين وكيفية أدائها مع ارسال بعض الصور والفيديوهات لهم والتي توضح كيفية تطبيقها وتم تطبيق التمارين البدنية على العينة احياناً صباحاً واحياناً مساءاً بمقدار (ساعة واحدة) في اليوم والتي ادت الى تقليل و خفض التوتر والقلق وتم تطبيقها في المنزل كونها لا تحتاج الى أدوات. 


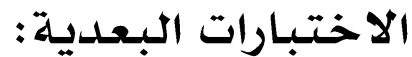

قام الباحثان باجراء الاختبارات البعدية لمقياس التوتر النفسي بعد الانتهاء من تطبيق التحارين البدنية وذلك يوم الاربعاء (1/ / / 20 200m عoo على جموعتين البحث الضابطة و التجريبية والبالغ عددهم (200) طالب من طلاب قسم التربية البدنية وعلوم الرياضة في كلية المعارف الجامعة وبعد انتهاء الطلاب من الإجابة على فقرات المقياس ضمن مدة تتراوح بين(15 دقيقة )، تم جمع الاستمارات وتفريغها في استمارات خاصة لغرض معالجتها احصائياً.

\section{الوسائل الإحصائية} تم استخدام الحقيبة الاحصائية SPSS.

\section{عرض النتائج وتحليلها ومناقشتها:}

\section{عرض نتـائج الاختبـارات القبليـة والبعديـه للمجهمـوعتين التجريبيـيـة والضـابطة فِ}

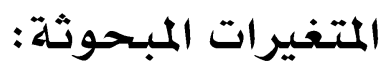

جدول (2) يبين الاوساط الحسابية والانحر افات المعيارية وقيمة ت المحسوبة بين الاختبارين القبلي والبعدي وللمجموعتين التجريبية والضابطة في درجة التوتر تحت مستوى دلالة 0.05

\begin{tabular}{|c|c|c|c|c|c|c|c|c|c|c|}
\hline \multirow{2}{*}{ الاحصائية } & \multirow{2}{*}{ مستوى } & \multirow{2}{*}{ قلميمة (ت) } & \multirow[t]{2}{*}{ عَ'ف } & \multirow[t]{2}{*}{ س-ف ف } & \multicolumn{2}{|c|}{ الاختبار البعدي } & \multicolumn{2}{|c|}{ الاختبار القبلي } & \multirow[t]{2}{*}{ المجاميع } & \multirow[b]{2}{*}{ ت } \\
\hline & & & & & $\varepsilon$ & س- & $\varepsilon$ & س- & & \\
\hline معنوي & 0,000 & 22,250 & 8,624 & 19,18 & 4,725 & 29.43 & 5,272 & 48,61 & التجر يبية & 1 \\
\hline معنوي & 0,000 & 14,812 & 6,137 & 9,08 & 6,613 & 39,85 & 4,632 & 48,93 & & 2 \\
\hline
\end{tabular}

يمكن ملاحظة من الجلدول اعلاه ان الوسط الحسابي لمقياس التوتر النفسي في الاختبار القبلي للمجموعة التجريبة بلغ (4,61 8 ) بانحراف معياري (5,272)، وبلغ الوسط الحسابي في الاختبار البعدي (29,43) بانحراف معياري (4,725)، وبلغ متوسط الفروق بين الاختبارين (19,18)، وبلغ انحراف الفروق 
(8,624)، وبلغت قيمة ت المحسوبة (22,250) وعند مقارنة مستوى الخطأ البالغ (0.000) وهو اصغر من مستوى الدلالة 0.05 ما يدل على ظهور فروق معنوية بين الاختبارين القبلي والبعدي ولصالح الاختبار البعدي . n

وقد بلغ الوسط الحسابي لمقياس التوتر النفسي في الاختبار القبلي للمجموعة الضابطة (48,93) وبانحراف معياري قدره (4,632)، بينما بلغت قيم الوسط الحسابي في الاختبار البعدي (39,85) وبانحراف معياري قدره (6,613) وقد بلغ متوسط الفروق (9,08) وبلغ انحراف الفروق (6,137) وان قيمة ت المحسوبة قد بلغت (14,8 12 )، وعند مقارنة مستوى الخطأ والبالغ (0,000) مع مستوى الدلالة البالغ (0.05) نجده اقل قيمة من مستوى الدلالة مما يدل ذلك على ظهور فروقات معنوية بين الاختبار القبلي والاختبار البعدي ولصالح الاختبار البعدي.

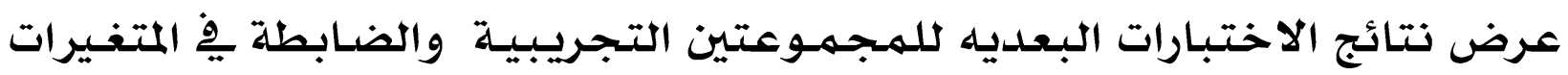
المبحوثة:

جدول (3) يبين الاوساط الحسابية والانحر افات المعيارية وقيمة ت المحسوبة بين للمجموعتين التجريبية والضابطة في الاختبار البعدي لدرجة التوتر تحت مستوى دلالة 50

\begin{tabular}{|c|c|c|c|c|c|c|c|c|}
\hline \multirow{2}{*}{ الاحصائية } & \multirow{2}{*}{ مستوى الخطأ } & \multirow{2}{*}{ قالمحسة (ت) } & \multicolumn{2}{|c|}{ المجموعة الضابطة } & \multicolumn{2}{|c|}{ المجموعة التجريبية } & \multirow[t]{2}{*}{ المتغيرات } & \multirow[t]{2}{*}{ 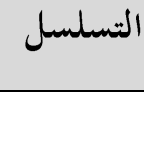 } \\
\hline & & & $\varepsilon$ & س- & $\varepsilon$ & س- & & \\
\hline معنوي & 0,000 & 12.769 & 6,613 & 39,85 & 4,725 & 29,43 & درجة التوتر & 1 \\
\hline
\end{tabular}

يمكن ملاحظة من الجدول اعلاه ان الوسط الحسابي لمقياس التوتر النفسي في الاختبار البعدي للمجموعة التجريبة بلغ (29,43) بانحر اف معياري (4,725)، وبلغ الوسط الحسابي في الاختبار البعدي للمجموعة الضابطة (39,85 ) بانحر اف معياري (6,613)، وبلغت قيمة ت المحسوبة (12,769) وعند مقارنة مستوى 
الخطأ البالغ (000) وهو اصغر من مستوى الدلالة 0.05 مما يدل على ظهور فروق معنوية في الاختبارات البعدية بين المجموعتين التجريبية والضابطة ولصالح المجموعة التجريبية.

\section{مناقشة النتائج}

يلاحظ من الجداول أعلاه هناك فروق معنوية بين المجموعتين التجريبية والضابطة ولصالح المجموعة التجريبية في مقياس التوتر النفسي ويعزوا الباحثين سبب ذلك الى التمارين البدنية المستخدمة حيث كانت هذه التمارين ذات فائدة ومناسبة لمستوى العينة وايضاً تتميز بالتنوع والتجديد وايضاً كانت شاملة لجميع أجزاء الجمسم مما أدى الى خفض مستوى التوتر النفسي للطلاب وبالإضافة الى انها تمنحهم القوام الجميل وتخلصهم من الضغوط و التوتر والكثير من التشوهات في الجسم، بخلاف المجموعة الضابطة التي لم تستخدم التحارين البدنية فقد يؤدي المى زيادة مستوى التوتر والقلق وان عدم ممارستهم للأنشطة الرياضية والتمارين البدنية قد تسبب لمم تشوهات في الجمسم بالإضافة المى السمنة والكثير من الامر اض النفسية.

\section{النتائج والتوصيات:}

النتسائج:

1 - تفوق المجموعة التجريبية التي استخدمت التمارين البدنية عن المجموعة الضابطة في خفض التوتر

النفسي.

2 - ان استخدام التمارين البدنية ساعد في خفض التوتر النفسي لدى الطلاب وبالتالي التمتع بحياة صحية خالية من الضغوط والامراض. 


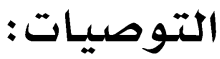

1 - ضرورة ممارسة التمارين البدنية بمختلف انواعها اثناء الجلموس في البيت فهي تساعد على التخلص من

التوتر النغسي.

2 - ضرورة الكشف عن مستوى التوتر النفسي والضغوط من اجل التغلب عليها.

المصادر

1. احمد ابو اسعد ، دليل المقاييس والاختبارات النفسية والتربوية ): مركز ديبونو لتعليم التفكير، الاردن، 2011)

2. ثامر محمد ذنون، منهل خطاب سلطان، التوتر النفسي وعلاقته بمستوى الانجاز الرياضي للاعبي منتخبات كليات

جامعة الموصل لبعض الألعاب الفردية والفرقية: (بجلة الرافدين للعلوم الرياضية، المجلد 17، العدد

.88 ص) 56,2011

3. مازن عبد الهادي، التمارين البدنية، (بحث منشور، جامعة بابل، 2014) ص212.

(1) مازن عبد الهادي ,التمارين البدنية, (بحث منشور , جامعة بابل ,2014)ص12

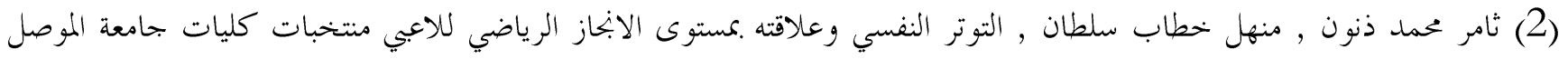

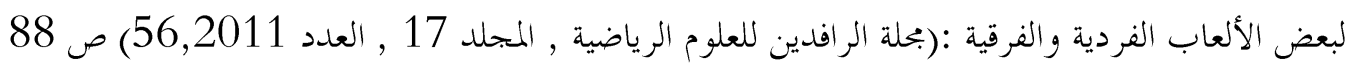

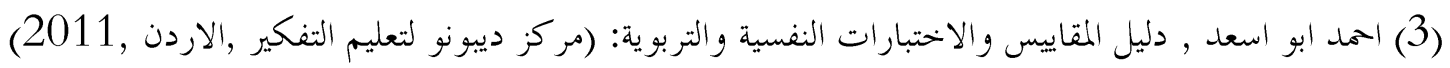




\section{ملحق (1)}

\section{انموذج من التمارين البدنية}

\begin{tabular}{|c|c|}
\hline التمارين البدنية & \\
\hline 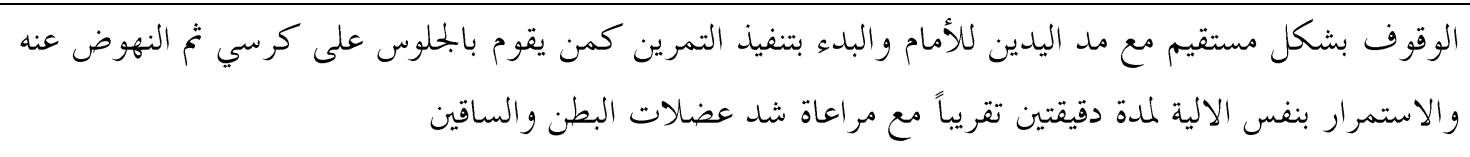 & \\
\hline 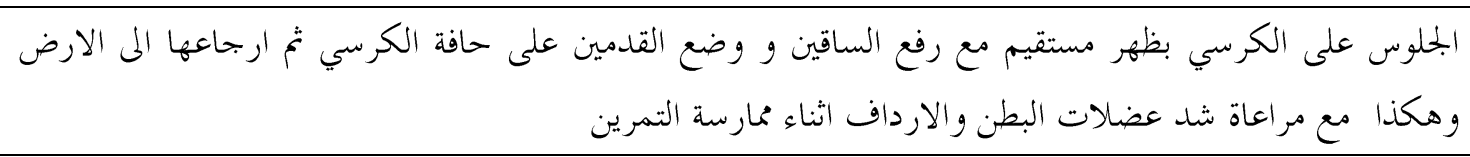 & \\
\hline 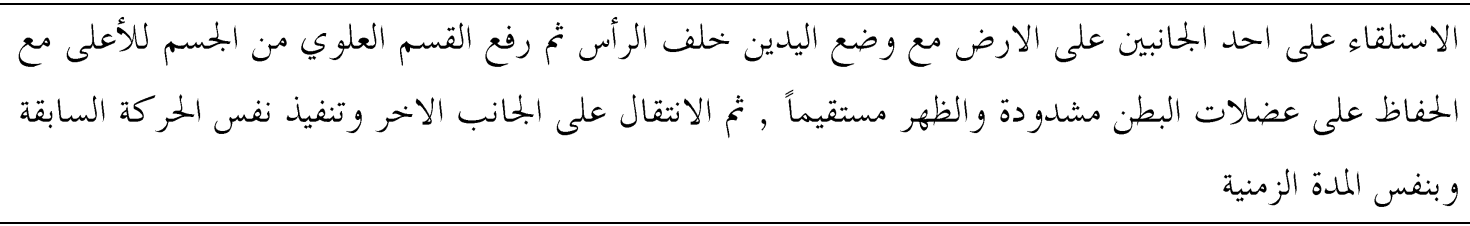 & \\
\hline 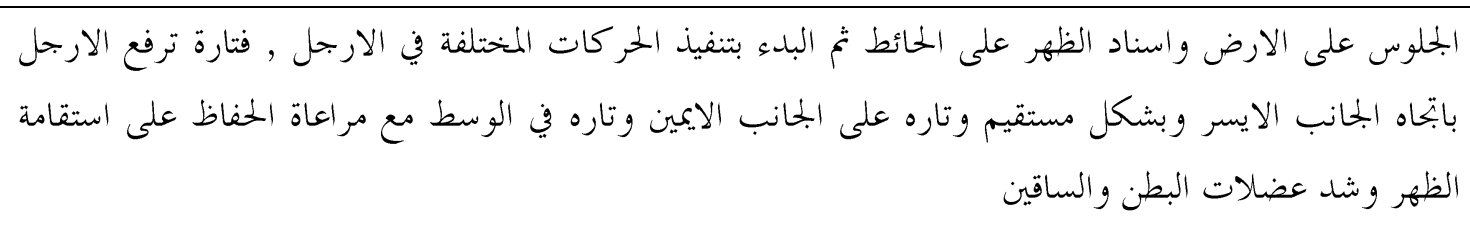 & \\
\hline 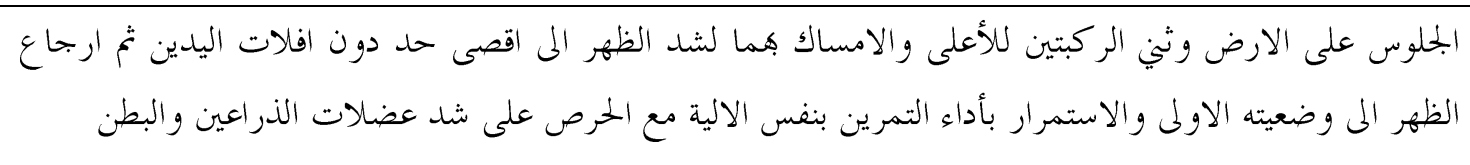 & \\
\hline 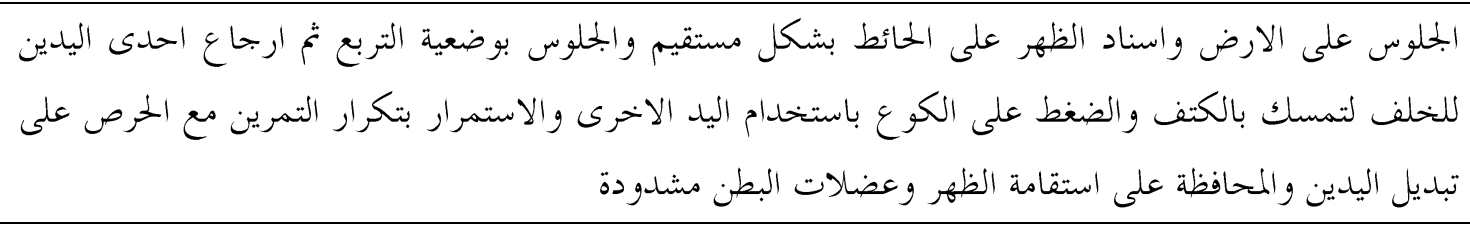 & \\
\hline 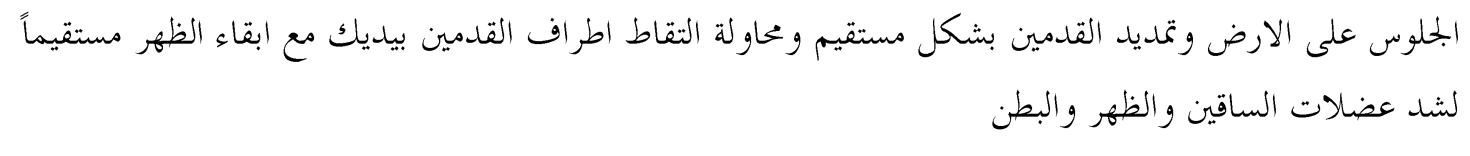 & \\
\hline استلقي على ظهرك اثني ركبتيك وضع يديك خلف رأسك وحاول رفع صدرك مرة الى اليمين ومرة اخرى الى & \\
\hline تمرين الضغط وهو استلقي على البطن وحاول رفع الجسم كله مع تثبيت الرجلين واليدين & \\
\hline 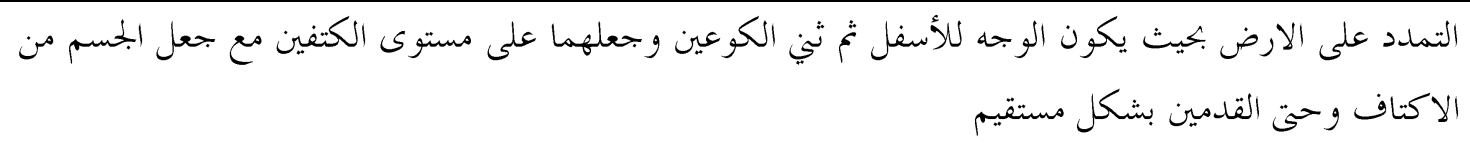 & \\
\hline
\end{tabular}




\section{ملحق (2)}

مقياس التوتر النفسي

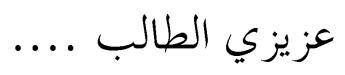

فيما يلي بحموعة من الفقرات التي تصف مشاعر الفرد يرجى قراءة كل فقرة و وضع علامة (لّ) في العمود المقابل لها لبيان مدى انطباق تلك الفقرة على وضعك.

$$
\begin{aligned}
& \text { اسم الطالب :- } \\
& \text { المرحلة :- }
\end{aligned}
$$

\begin{tabular}{|c|c|c|c|c|}
\hline لا تنطبق علي & تنطبق علي & تنطبق علي كثيرا & 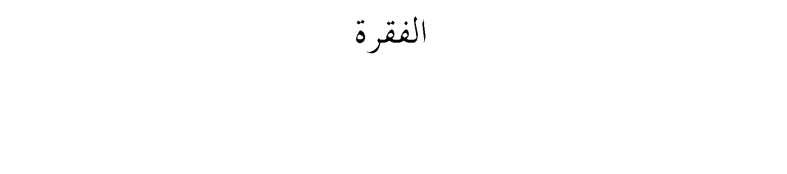 & 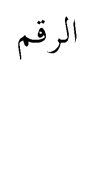 \\
\hline & & & اعاني كثيرا من الصداع & 1 \\
\hline & & & سلدما اجلس للراحة والاسترخاء اجد نفسي منهمكا بأفكار & 2 \\
\hline & & & يلازمني شعور دائم بعدم الارتياح & 3 \\
\hline & & & ن ادرا ما اشعر بالاسترخاء التام & 4 \\
\hline & & & اشعر بعدم القدرة على التركيز في ما اقوم به من اعمال & 5 \\
\hline
\end{tabular}

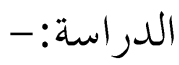




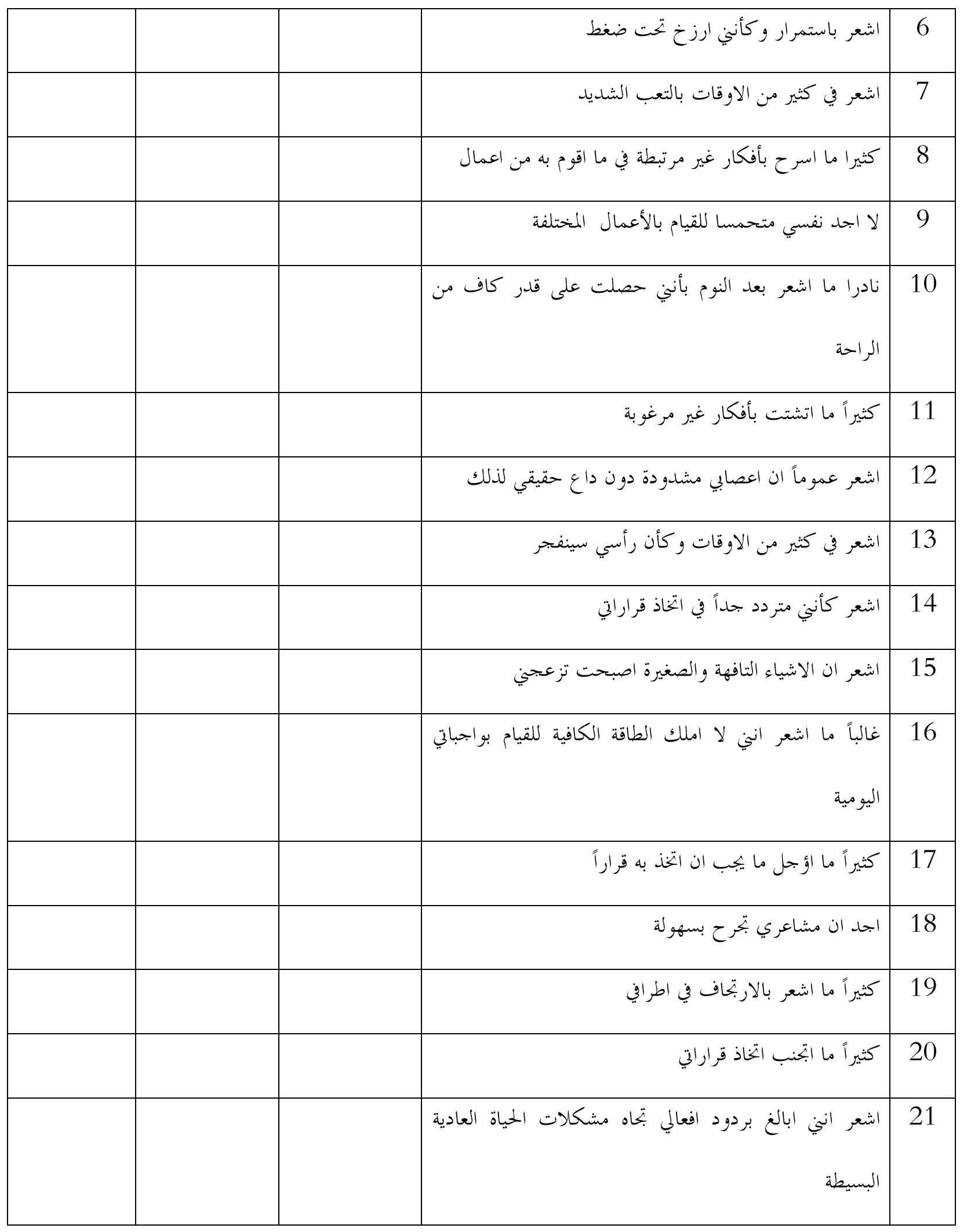




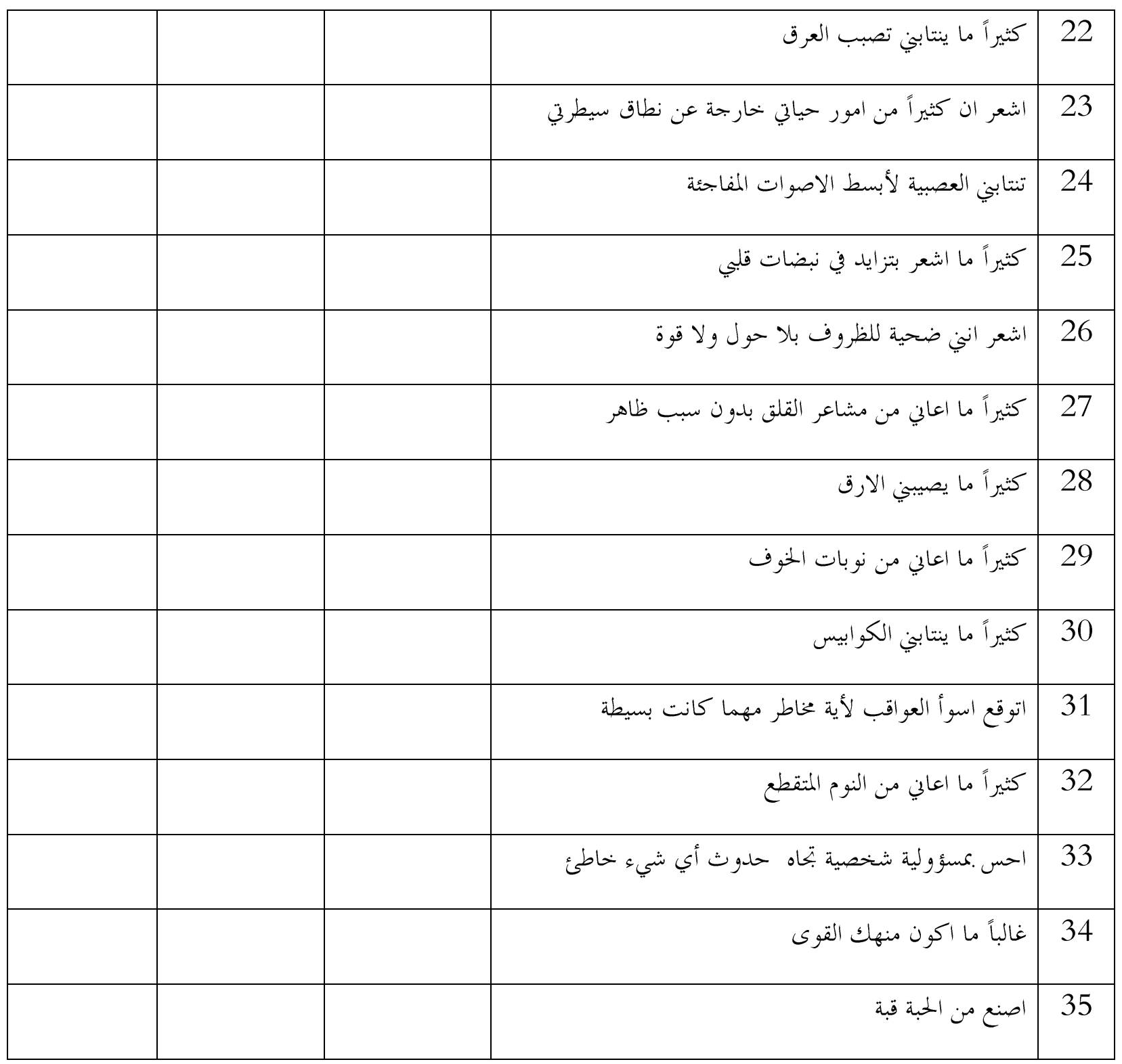

